\title{
La lectura sartreana de Mallarmé: la poesía crítica como negación pura
}

\author{
Sartre's Lecture on Mallarmé: \\ Critic Poetry as Pure Negation
}

\author{
SANTIAGO BELLOCQ \\ UNIVERSIDAD NACIONAL DE SAN MARTÍN (ARGENTINA)
}

Recibido: 25/02/2019 Aceptado:11/03/2019

\section{RESUMEN}

El viraje en la concepción sartreana de la poesía, ya comenzado en su Saint Genet y Orphée noir, se radicaliza en la biografía existencial que hace de la obra y la persona de Stéphane Mallarmé. Sartre plantea la posibilidad de que la poesía efectivamente pueda comprometerse (algo que parecía negado en Situations II) debido a su altísima potencia negativa-destructiva, que conduce a una manifestación de la esencia negativa, conflictual y «fracasada» de la conciencia como ser-para-sí llamando a su libertad y dando lugar así a una poesía crítica, hermana de la «literatura total».

\section{PALABRAS CLAVE}

SARTRE, MALLARMÉ, POESÍA, NEGATIVIDAD, COMPROMISO

\begin{abstract}
Sartre's turn on his notion of poetry, which already begun in his Saint Genet and Orphée noir, gets radicalized in his existential biography of Mallarmé's work and life. Sartre suggests that it is effectively possible for poetry to commit (something that seemed denied in Situations II) because of its extreme negative-destructive power, which leads to the manifestation of consciousness' negative, conflictive and «failed» essence, calling the being-for-itself to take over its freedom and giving birth in this way to a «critic poetry», relative of Sartre's «total literature» notion.
\end{abstract}

KEYWORDS

SARTRE, MALLARMÉ, POETRY, NEGATIVITY, COMMITMENT

(C) Contrastes. Revista Internacional de Filosofía, vol. XXIV-Nº3 (2019), pp. 7-23. ISSN: 1136-4076

Departamento de Filosofía, Universidad de Málaga, Facultad de Filosofía y Letras Campus de Teatinos, E-29071 Málaga (España) 


\section{INTRODUCCIÓN: ¿UN POETA COMPROMETIDO?}

PARECE SORPRENDENTE QUE ALGUIEN tan comprometido políticamente como Sartre tuviera en tan alta estima a un poeta tradicionalmente considerado como emblema de la irresponsabilidad artística, como ejemplo claro de una poesía impenetrable y alejada de la historia que por defecto rechaza a todo lector «vulgar» que no hubiera sido iniciado en los ritos órficos y mistéricos que exige su comprensión; y sin embargo, nuestro autor declara que Mallarmé goza de toda su simpatía, ya que «está comprometido conscientemente»:

Mallarmé debía ser muy distinto de la imagen que se ha dado de él. Es nuestro más gran poeta. Un apasionado, un furioso. ¡Y dueño de sí mismo hasta poder matarse por un simple movimiento de la glotis!... Su compromiso me parece tan total como posible: social tanto como poético. ${ }^{1}$

Mallarmé es quizás la figura que mejor encarne para Sartre su idea de literatura total, cosa que demanda para existir precisamente un compromiso total del artista. Parecería que esta afirmación desdice aquellas lecturas superficiales en las que se critica a Sartre que rechaza totalmente la posibilidad de una poesía comprometida, a raíz de ciertas postulaciones plasmadas en Situations II en las que opone prosa y poesía. Esencialmente, muestra ahí que la diferencia reside en cómo éstas toman a la palabra y el lenguaje, si como un signo-significado o como signo-cosa[en-sí]. Según Sartre, la actitud poética considera las palabras como cosas y no como signos propiamente dichos, ya que normalmente éstos, por su ambigüedad, pueden tanto ser voluntariamente atravesados como un cristal transparente hacia una instancia que se encuentra más allá de él, es decir, hacia la cosa significada, así como pueden ser considerados en su misma realidad de objetos. Un hombre que habla o que escribe en prosa se encuentra más allá de las palabras, entre los objetos indicados; un poeta se encuentra con las palabras como una barrera, y no va más allá pues ellas mismas son en sí el objeto auto-significado. De esta manera la poesía «estancaría» la conciencia humana en sus imágenes y sentidos opacos, quedándose sólo en ellos sin trascender hacia un significante que la convoca a asumir su libertad. Sin embargo, ya hacia 1948 en su análisis de los poetas negros y malgaches que figura en Orphée noir como en su biografía existencial de Jean Genet parece haber un cambio de percepción, en el que la poesía posee una potencia negativa-destructiva (revolucionaria, incluso) que de alguna manera sí permite un llamamiento a la libertad en tanto refleja críticamente la esencia humana al mostrarla como imposibilidad y fracaso.

1 Sartre 1972 [1973], p. 13. El subrayado es mío. 
¿Pero por qué entonces Mallarmé? ¿Qué hay en su vida y en su poesía para que el filósofo lo tome como paradigma de la Poesía misma? Será, quizás, que encuentra en su drama ontológico-poético la presencia latente de aquello que hace a la esencia de la conciencia, aquello que constantemente se sustrae pero que nos «sugiere» centelleantemente su experimentación: la negatividad pura.

\section{SiTUACIÓN DEL POST-MODERNO}

E1 «caso Mallarmé» interesa especialmente a Sartre a partir de 1948, curiosamente luego de Orphée Noir y antes de comenzar su estudio sobre Genet. $^{2} \mathrm{Si}$ bien el texto que nos queda resulta fragmentario e incompleto, ${ }^{3}$ el autor buscó por primera vez intentar introducir herramientas del marxismo en una biografía existencial, a diferencia del Baudelaire que pertenece aún a ese cuerpo de textos temáticamente ubicado entre la guerra y sus años fenomenológicos previos, lo cual es un hito no sólo para estos psicoanálisis sino para toda su futura producción de textos como podemos ver a partir de Situations II; es un ensayo que, de triunfar, le aseguraría una herramienta conceptual enormemente potente, que es la que finalmente se puede apreciar en plenitud en la Crítica de la razón dialéctica. Como nos dice Sartre:

El verdadero enigma por resolver aquí es más complejo: se trata de saber cómo se puede utilizar simultáneamente dos métodos que pretenden excluirse, cómo un mismo conjunto temático puede servir de emblema tanto de un destino personal y sexual como de un momento de la historia social. Y si estuviera probado que se debe tener en cuenta estos dos sistemas a la vez, ¿qué relación se debe establecer entre estos dos órdenes de significación? ¿Interpenetración, separación absoluta [...]? Si hemos elegido el caso de la 'esfinge oscura' de Tournon, es porque nos parecía una ocasión privilegiada para afrontar en lo concreto la interpenetración del psicoanálisis y la del marxismo. ${ }^{4}$

2 Ya por ese año escribe a Simone de Beauvoir: «estoy deslumbrado con Le coup de dés (poema rigurosamente existencialista...)» (Cf. Sartre 1983).

3 Además del breve artículo publicado en 1953 por Queneau en el tomo III de Ecrivains célèbres y luego republicado en Situations $I X$, quedan algunas notas del trabajo principal que Sartre habría emprendido desde 1948 a 1952, trabajo que iba siendo alternado con la biografía sobre Genet y años después dejado de lado, aunque Sartre siempre afirmó que le hubiera gustado continuarlo. Lo que se conserva de ello son unas notas incompletas publicadas en 1979 en la revista Obliques bajo el nombre de «El compromiso de Mallarmé»; el resto se perdió o fue destruido, probablemente en los atentados realizados en el domicilio de Sartre por la OAS a raíz de su posición durante la guerra de Argelia.

4 Sartre 1986 [2008], p. 89. A notar aquí que «psicoanálisis» incluye implícitamente toda la fenomenología de la existencia desarrollada previamente. 
Este abordaje se puede ver claramente manifiesto en la primera parte, «Los herederos del ateísmo», en el análisis que realiza de la época y el contexto histórico-poético en el que surge Mallarmé. Debemos profundizar en qué medida la condición epocal determinará la situación y el proyecto mallarmeano, insertado en línea con el descubrimiento de la Nada como gran tema y verdad del poema (y del mundo y del lenguaje).

Para Sartre, lo que se efectiviza con la caída de la monarquía es la muerte de Dios y, con él, del Hombre y la Poesía, temas centrales todos propios del romanticismo. El poder de análisis burgués desintegró todas las síntesis monárquicas y aristocráticas y con ello toda la estructura del Ser social y simbólico que sostenían; pero en el momento en que la burguesía entendió que ella también debía desintegrarse para dar lugar a un nuevo tipo de sociedad, ${ }^{5}$ reaccionó con mala fe quedando en un limbo ideológico y espiritual que Nietzsche bien llamó «nihilismo europeo». La Revolución crea un «humanismo del no-ser», y en ese contexto «los poetas, del Parnaso al Simbolismo, no harán sino llevar hasta lo sublime la imagen negativa que la clase poseedora quiere dar de sí misma». ${ }^{6}$

Así es que, muerto Dios, la palabras se derrumbaron quedando solo un nominalismo desesperado. Para Sartre lo que más lamentan estos poetas es el hecho de que fueron hechos ateos, anulándoseles la posibilidad de ser ellos quien eventualmente pudieran rechazar la fe. A su vez, se les condiciona en el espíritu de la Impotencia, una constante en todos los poetas de la época, consecuencia directa de la irreligión; lo que brota es una suerte de maniqueísmo ateo en donde la oposición fundamental se da entre la Nada y el Ser: «con la desaparición del ser-en-sí, la infinita colección de los seres se ha ahogado en la contingencia [...] A nuestros ateos-a-su-pesar, todo lo que es les evoca la imagen absurda y vana de su ser [...] Por lo demás si Dios no existe, Ser y Materia son términos intercambiables; el Ser es dispersión, inercia y exterioridad». ${ }^{7}$ Ahora bien, si se está condenado a pertenecer a un régimen de mineralidad, ¿qué opciones le quedarían al hombre para elevarse

5 «[La burguesía] se niega a conocerse en su verdad: vería la muerte en el espejo; presiente y quiere ignorar que fue la clase que se encargó de abolir la Nobleza en nombre de una sociedad sin clases. Esta sociedad futura es su término y su ruina, su razón de ser y su negación, pero esto no se dirá: sería confesar que se lleva en sí mismo su propia destrucción y que uno no puede realizarse sin anonadarse» (Ibíd., p. 54).

6 Ibid., p. 56. Recordamos que los poetas a los que se está referendo Sartre son aquellos contemporáneos de Mallarmé, los movimientos o grupos a los que perteneció o con los que convivió; particularmente, las descripciones que hace Sartre refieren especialmente al Parnaso y al Simbolismo, metiendo en la misma canasta al Decadentismo y al Malditismo. Todos ellos son la «generación» a la que haremos constantemente referencia.

7 Ibid., p. 37 
por encima de la materia? Pues precisamente, el hecho poético mismo, pero en la renuncia a ser un espejo del mundo inteligible (muerto ahora), en la anulación del azar y el determinismo por algo nuevo ex nihilo, es decir, por la creación poética. Siendo dos las maneras de afirmarse contra la materia, ser creatura (opción obviamente anulada) o ser creador, los jóvenes poetas apostarán por crear algo pero desde la óptica del Ideal y la Belleza, únicos contrarios sólidos en ese naufragio universal. ${ }^{8}$ Se abre así un juego de reflejos en el que el poeta se siente relativamente cómodo: el ser en su pura existencia desnuda es negación de toda manera de ser, y la manera de ser, pura determinación subjetiva, acaba por ser en sí misma una apariencia y por consiguiente una negación del Ser. Vemos que es algo muy similar a lo que ocurría con Genet, solo que en un momento más originario aún. Para Sartre, en este tiempo particular de la historia literaria el Artista no cree ya en el arte porque ha perdido su garantía divina; pero como es el universo entero el que ya no tiene sustento, entonces sólo le queda otorgarle su fe al arte -y a nada más. Así es que la Poesía descubre una misión nueva, reconstituir contra la Verdad una nobleza fantasma, un mundo nuevo de apariencias, de sugestiones, un mundo de Sueño, es decir, un mundo imaginario de símbolo. Frente a las verdades de la ciencia y el materialismo en boga establecerá un «orden de lo incomunicable»; la belleza será su principio selectivo, en apariencia popular y ofrecida a todos, pero accesible luego a unos pocos privilegiados: una ruptura de nivel en lo más profundo de la sociedad. El régimen de lo Ideal es el de un Deber-ser que se exige como nuevo fundamento fantasma de lo real; si un poeta se sacrifica para demostrar por su spleen que algo tiene que existir, aunque sea una palabra, algo se habrá salvado del drama cósmico. Así es que el canto de esta nueva generación de poetas canta lo mismo que sus padres románticos, pero sobre un vacío: habrán elegido, «de una vez por todas, su tema poético: el no-ser» $;^{9}$ y con él, todas las categorías negativas del fracaso que de ahí se desprenden: el Pasado antes que el Presente, el artificio antes que la naturaleza, el deseo a la saciedad, la indiferencia al deseo. Reemplazaron la «alegre dilapidación de las riquezas» propia a la aristocracia-burguesía de la que venían por una negación sistemática de la realidad, de su clase y su sociedad, del lenguaje.

8 Sartre insiste en que esta contraposición Idea-Materia es un rasgo esencial de la época, que está realmente hundida en el no-ser: «a decir verdad, estas dos Nadas no son de la misma naturaleza: a una, puro despliegue multicolor de cualidades ideales, le falta el Ser; en cuanto a otra, si se la despoja de todas las irisaciones que nuestra fantasía le presta, no es más que ser incalificable. Así nos encontraríamos de nuevo con esta dialéctica hegeliana del Ser y del No-Ser, pero vivida: el Ser puro no se distingue en absoluto del No-Ser puesto que no es nada; y la Nada, como se puede soñar con ella, es preciso que, en cierta medida, sea.» (Ibíd., p. 51).

9 Ibid., p. 32 
Esta negatividad es lo que alimenta los proyectos poéticos y los temas del Parnaso, del cual se desprenderá luego el élan simbolista. ${ }^{10}$ Hijos y detractores de Hugo, pero más de Baudelaire, son los herederos del romanticismo por excelencia y los pregoneros principales del art pour l'art, siempre desde la negación de sus predecesores. Así es que acusando al romanticismo de un exceso de lirismo y de expresión subjetiva demasiado pastosa buscan una «despersonalización», aquella impasibilidad que ya mencionamos antes; si utilizan el «yo poético» es para disolver su singularidad en la experiencia general. Rechazan a la vez a la burguesía y a la acción política, ampliando la brecha que los separa de las masas fundando así una nueva aristocracia bohemia, dandy al mismo tiempo que decadente y generalmente pobre. $\mathrm{Su}$ negatividad llega al punto de rechazar totalmente su ser-en-la-época, desinteresándose de todo cuando acontecía que no tuviera que ver con la perfección y la purificación del arte, con la búsqueda de la belleza ideal. La autonomía del arte vivirá en lo más inaccesible de la torre de marfil a la que estos poetas se exilian voluntariamente. Los simbolistas, como los parnasianos, también tomarán a Baudelaire como faro tutelar, buscando desarrollar más ampliamente aún la purificación y la autonomía de la poesía pero mediante una nueva valorización de la dimensión sensible del lenguaje: fundan una estética de la sugestión, una poesía casi impresionista, donde como dirá el joven Stéphane de lo que se trata es de «pintar no la cosa sino el efecto que produce»: ${ }^{11}$ destellos, iluminación recíproca con los fuegos de las palabras incendiadas, musicalidad, destrucción de la significación. Pero en el fondo, como bien señala Sartre, «esta confraternidad de iniciados tiene su misterio: el de la Transustanciación de la Nada en Absoluto, del No en Sí, de lo Imposible en Necesario». ${ }^{12}$ Se creen comprometidos con su época, considerada una gran tragedia social que transforman en catástrofe cósmica, pues «es más cómodo y menos peligroso enfriar el Sol con el pensamiento que atacar el orden social». Y además, en el plano existencial, se estancan en un momento trunco del despliegue de la conciencia: «a falta de amarse a sí mismos, no se aceptan más que como pura negación de ellos mismos. Se quedan pues en el terreno de la conciencia desgraciada y el acto puro de negatividad constituye, hasta 1890, la única relación íntima consigo mismo». ${ }^{13}$ Sartre considera que este protestantismo es sincero, que simplemente «la negatividad se ha tomado por

10 Cf. Mortelette 2005 y Campa1998.

11 Carta a Cazalis, 30 de octubre de 1864: «....invento una lengua que debe necesariamente brotar de una poética muy nueva, que podría definir en estas palabras: pintar, no la cosa, sino el efecto que ella produce. El verso no debe, ahí, componerse de palabras sino de intenciones, y todas las palabras deben borrarse delante de la sensación». (Cf. Mallarmé 1995).

12 Sartre 1986, p. 42

13 Ibid., p. 61 
su propio fin»; pero al mismo tiempo ve en toda esa generación una cuota de mala fe, puesto que «la situación poética no ha sido vivida» de manera total, nadie la ha interiorizado hasta el final, nadie ha encarnado sacrificialmente la Idea poética; Cazalis, Lefébure, Mendès, todos abandonan a mitad de camino. La gran excepción será, por supuesto, Mallarmé.

\section{GÉNESIS DEL PROYECTO POÉTICO MALLARMEANO}

Mallarmé se muestra como la imagen refleja de lo que el siglo ha hecho de él, y por eso sus contemporáneos han encontrado en él una guía, un ejemplo; pero a pesar de ello, Sartre afirma que sus cófrades no lo reconocen totalmente pues él «se ha empeñado en vivir según sus principios. En lugar de jugar con [los] sentimientos distinguidos [...] de los poetas, parece como si hubiese sido su víctima voluntaria, devorado por ellos. Él no se contenta con degustar la decadencia [...]: la encarna, la simboliza por su propia decadencia, se hace 'viejo...embrutecido...anulado'», ${ }^{14}$ como si la poesía negativa del siglo XIX hubiera decidido suicidarse solemnemente en él. Los poetas que lo rodean no tienen para Sartre otro remedio que recurrir a la prédica de virtudes que antes despreciaban, pues la misma existencia de Mallarmé los obliga a aclarar su propia autenticidad, más allá que la oculten por la mala fe. Por otra parte, sus «temas poéticos» son los mismos que los de su generación, pero radicalizados: «'la gran corriente del amor sobrenatural', el erotismo incestuoso, el gusto por el fracaso y por el No-Ser, el idealismo desesperado, el maniqueísmo, el preciosismo, el nihilismo: son motivos dispersos del espíritu objetivo de la época, expresan tanto la coyuntura histórica y social como la historia de una sensibilidad individual, si no más»..$^{15}$

Sartre da una gran importancia al condicionamiento del niño, tal como ocurrió con Genet, desplegando una serie de interpretaciones de cuño freudiano respecto de su relación con su familia y especialmente con su madre muerta prematuramente, que serán la causa de su experiencia fundamental de la Nada ${ }^{16}$ y de su relación fundamental con el mundo como negación.

14 Ibid., p. 81

15 Ibid., p. 86

16 «Desgraciadamente, profundizando el verso hasta ese punto, he encontrado dos abismos que me desesperan. Uno de ellos es la Nada, a la que llegué sin conocer el Budismo, y estoy todavía demasiado desolado como para poder creer incluso en mi poesía y volver a ponerme a trabajar, que este pensamiento aplastante me hace abandonar. Sí, yo lo sé, no somos más que vanas formas de la materia - pero bien sublimes para haber inventado a Dios y nuestra alma. ¡Tan sublimes, mi amigo! que quiero darme ese espectáculo de la materia, tomando conciencia de ella y, sin embargo, lanzándose precipitadamente hacia el Sueño que ella no podría ser, cantando el Alma y todas las divinas impresiones parecidas que fueron acumuladas en nosotros desde los primeros tiempos, y proclamando delante de la Nada que es la verdad esas gloriosas mentiras! 
Inicialmente el niño vive el Todo como el amor por su madre, fusionada por entonces con el Mundo. La dulce mirada materna, el elemento constituyente del niño, se pierde con su muerte y el niño es desplazado fuera (como un «ser de lejanías») hacia un plano de distancias, de vacío: las cosas surgen en su verdad, y la totalidad del Ser se le revela como una «hueca nada». El niño se descubre naturalmente como llamada, como deseo, pero como deseo de una ausencia, de una muerta, del pasado: para Mallarmé

La aparición de lo real es la desaparición vertiginosa de la esperanza, la presencia absoluta de Todo es la ausencia universal de cada uno [...]. Todos los objetos son igualmente insignificantes; y su equivalencia universal nace de que se manifiestan sobre la base de una común negación: todos tienen ese mismo carácter formal de no ser el objeto deseado [...]; es la Nada (Rien), precisamente, la que lo compromete todo: lejos de ofrecerse a la intuición directa, el Ser surge del desvanecimiento del no-Ser; esta generación indirecta es, ante todo, la destrucción de la ausencia, en fin, una negación de la negación. ${ }^{17}$

El «niño Stéphane» se irrita y se repliega por ese desgarro íntimo, afirmándose contra el Ser y el Mundo quienes flotan en el «lago mortecino de la Nada». Si para un niño "común» y feliz lo primero es el descubrimiento de la plenitud, surgiendo luego la negatividad como una instancia derivada, para este huérfano es al revés y la Nada pasa a ser la única vía de acceso a lo real. Así es que «ya desde los seis años, el niño concibe el ser-en-el-mundo como un exilio y su vida se abre sobre una irremediable experiencia de fracaso», ${ }^{18}$ enajenado por la muerte de la Otra, intentará casi patológicamente reproducir sobre la superficie del ser aquella Mirada unificadora de su madre en síntesis evanescentes: la «luz corrosiva del Valor» disolverá la abundancia bruta e insignificante del Ser. La totalidad de su ser-en-el-mundo se ve afectada por la ausencia originaria, de lo que no puede surgir sino un pro-yecto trunco, de fracaso y negación total: de esta manera «va a negar el Mundo, instalar en su propio ser esta Ausencia, identificarse con ella. Él era negado, ahora se hace Negador [...]: lo rechazará todo»». ${ }^{19}$

¿Pero cómo hundir la totalidad del universo en la nada, cómo hacer de la Totalidad una Ausencia? Primeramente va a adoptar una actitud fundamental, ser conciencia de conciencia, conciencia reflexiva, que se niega a aceptar lo

Tal es el plan de mi primer volumen Lírico, y tal será quizás su título, La Gloria de la Mentira o La Gloriosa Mentira. Cantaré desesperando!...» (Mallarmé 1995, pp. 297-298). Sobre la «crisis de Tournon», $c f$. Laupin, P 2004, pp. 35-76 y Gallardo1998, pp. 9-28.

17 Sartre 1986, p. 97

18 Ibid., p. 98

19 Ibid., p. 109 
que es, incluso llegando al rechazo de sí mismo. Esta personalidad reflexiva, dirá Sartre, no es otra cosa que la negación abstracta de su personalidad empírica; sólo de ahí podría, en algún momento, surgir una obra reflexiva, es decir crítica. Pero este rechazo constante de sí, esta no-asunción constante de sí es ciertamente insostenible, como una especie de eterna duda metódica sin Cogito donde todo es desacreditado de antemano por aquella negación generalizada. El secreto, la única vía posible, será encauzar esa negación universal y concretarla: primero insertándola/encarnándola como lo más esencial de su existencia, segundo negando al mundo mediante una obra singular, concreta y total (aquello a lo que luego llamará «El Libro»). Y esto sólo podrá realizarlo en el plano del lenguaje. Como muestra Sartre, «el niño se librará de las fatalidades de su nacimiento si consigue crearse de nuevo. Que dé a luz a una obra para que pueda a su vez 'según ningún vientre sino el suyo, filial', renacer [...]. Y si pide a las palabras mejor que a los sonidos o que a los colores que le socorran, es porque adivina en ellas una secreta ambigüedad». ${ }^{20}$ Nombrar, en este caso, es destruir y crear a la vez. Citando a Hegel, Sartre señala que Adán logró dominar a los animales y a la creación al nombrarlos, es decir, al «anonadarlos en su existencia»: lo ideal entonces sería que el lenguaje sirviera para, con el mismo movimiento, nihilizar el mundo y recrearlo a través de las palabras. ${ }^{21}$ De esta manera el niño «rechaza la vida en nombre del poema que le queda por hacer»: como un chamán, a este poeta se le impone «el deber de recrearlo todo». Desde lo más profundo de la imposibilidad y el fracaso, desde la experiencia desgarrada de la ausencia, surge con su luz más pura la esencia de todo proyecto poético del que Mallarmé es el más alto ejemplo.

\section{DE LA IMPORTANCIA A LA EFICACIA DEL TRABAJO NEGATIVO DEL SUICIDIO}

Mallarmé, como todo poeta según nuestro filósofo, posee un imperativo categórico que consiste en crearse un Yo puro a través de la obra poética. Sartre traduce en términos kantianos la interrogación que este poeta se haría, algo así como «¿hay una razón pura poética?» o mejor «¿en qué condiciones es posible una poesía pura?»; respondería, siguiendo el juego, que ésta sólo podría nacer de la pura representación de ella misma, de una voluntad poética

20 Ibid., p. 116

21 En el Saint Genet Sartre cita unas páginas de Blanchot que refieren a Mallarmé y su uso del lenguaje: «Primero el lenguaje se sostiene en una contradicción: de una manera general, es aquel que destruye el mundo para hacerlo renacer en estado de sentido, de 'valores' significados; pero sobre su forma creativa, se fija solo sobre el aspecto negativo de mancha y deviene poder puro de contestación y transfiguración» (Blanchot, Faux-Pas, Nouvelle Revue Français, p. 44, citado en Sartre 1952, p. 345). 
autónoma que se considerara universal y «absolutamente poética». Pero si en Kant lo Ideal es quien orienta la acción libre de la voluntad, en nuestro poeta el Ideal (Azur, Absoluto o como lo llame) es la Nada pura, la objetivación del Rechazo, la conciencia de un vacío: en otra palabras es el spleen baudelairiano transformado, la Impotencia misma como rechazo radical del otro, del mundo y de sí mismo.

Como dijimos anteriormente la Impotencia es un rasgo de época, consecuencia directa de la Negación; como todo ha sido prohibido, no hay nada para decir. No se trata tanto de una turbación patológica ni de la elevadísima exigencia a la que Mallarmé se auto-sometía, sino de una esterilidad procedente de su intransigencia; bajo su mirada reflexiva donde el No se transforma en Sí, transformará su imposibilidad de cantar en canto de lo imposible. Ello puede verse patentemente en Herodias, la gran «culpable» según Mallarmé de tantas noches y años de esterilidad: lo que encontró ahí, como bien expresó en su carta, es la Nada, pues pretendió colocar lo Absoluto en ese poema y ese absoluto era nada precisamente. Desde entonces su preocupación y dolencia personal toma luego una amplitud cósmica mediante una lógica negativa: antaño la Inspiración era garantizada por la gracia divina; en este universo ateo donde todo es igual a sí solo hay «golpes de suerte» impotentes, bajo la sombra del fantasma de la Causa Sui, del Dios recién muerto; en ese contexto, el Hombre ${ }^{22}$ no será si primero no crea la obra; pero en Herodías la Obra escapará al Azar solo si consigue crear totalmente a su creador; Hombre y Obra deben sacarse a sí mismos de la Nada: de ahí que el gran tormento del poeta estéril sea un desgarro de la conciencia con alcance universal entre la necesidad absoluta del deber-ser poético y la imposibilidad radical de crear pues, como Mallarmé bien sabe, no se creará nada.

22 Sartre señala que Mallarmé (como él mismo) nunca creyó que el hombre pudiera ser conceptualizable, tan al tanto estaba de las contradicciones que le son esenciales. Si Mallarmé es el más grande de los poetas, es porque ha sido quizás el más grande de los hombres: «uno no piensa la realidad humana, sino que la vive, pues es la paradoja, el conflicto sin síntesis. El Hombre es ese ser al que se le empuja, con la espada en los riñones, para que se suba al trono de Dios y que no lo consigue. El Hombre es Drama. Este Drama, Mallarmé lo ha vivido» (Sartre 1986, p. 128). Mallarmé es presentado por Sartre casi como una nueva figura atea de Cristo, quien clavado en lo alto de la cruz de la negatividad pura se sacrifica y asume la totalidad de esta Tragedia: «en él van a enfrentarse, por todos, lo Singular y lo Universal, la Causa y el Fin, la Idea y la Materia [...]. Alguien va a nacer 'ambiguo' de dos personajes que parecen incompatibles: pues el profesor abucheado es el que será, nuevo Prometeo, el héroe de un drama ontológico; el funcionario humillado es el que, sin dejarse descorazonar un instante por la certeza del fracaso, ambicionará reemplazar a Dios [...]; el impotente es el que prestará sus ojos y su pensamiento a la Poesía y a la Humanidad para que puedan alcanzarse y verse, les prestará su mano para jugar su última suerte y tirar los dados...» (Ibid., p. 127). 
Llegado a este borde, el poeta se ha nihilizado al punto de considerar seriamente el suicidio, pues entiende que el hombre es definido por la Imposibilidad. La conclusión que de ahí surge es la siguiente: «si el hombre es imposible, hay que manifestar esta imposibilidad llevándola hasta el extremo en el que se destruye a sí misma. [...] El Ser solo produce el Ser; y si el Poeta elige el No-Ser como consecuencia de su no-posibilidad, la causa de la Nada es entonces el No: un orden humano se establece contra el Ser por la desaparición del propio Hombre», ${ }^{23}$ pues el Azar es ontológicamente relativo a la existencia humana. ${ }^{24}$ Sartre afirma que Mallarmé no dudaba que, de suicidarse, la humanidad entera se terminaría con él: su suicidio sería un genocidio que devolvería su pureza al Ser. Es lo que intentaron algunos de sus compañeros, aunque claramente sin mucho éxito. Pero si finalmente no lo hace es porque ha encontrado el secreto profundo de este acto: si el suicidio es eficaz, es porque remplaza la negación abstracta (y por ende inútil) de todo el ser por un trabajo negativo concreto y destructivo. Se da cuenta que la negación universal equivale a la ausencia de negación, ${ }^{25}$ algo que no percibieron los surrealistas: negar es un acto, y como todo acto debe insertarse en el tiempo y debe ser ejercido sobre un contenido particular; y si el suicidio

23 Ibid., pp. 144-145

24 «El Azar no existe en el Ser [...]; el Hombre lo hace aparecer confrontando su sueño, el orden de los fines, con el encadenamiento infinitamente infinito de las causas, que es la Realidad [...]» (Ibid., p. 130).

25 La negación de todo no puede ser una actividad destructiva, sino que es la simple representación de la noción negativa en general. Sartre inserta a Mallarmé en el momento hegeliano de la conciencia escéptica, quien realiza lo que en el estoicismo (como en la pretensión inicial del poeta) era la negación pura y abstracta. Citando a Hegel podemos reproducir la argumentación sartreana: «El escepticismo es la realización de aquello de que el estoicismo era solamente el concepto -y la experiencia real de lo que es la libertad del pensamiento; ésta es en sí lo negativo [...]. El pensamiento deviene el pensar completo que destruye el ser del mundo múltiplemente determinado, y la negatividad de la autoconciencia libre se convierte, en esta múltiple configuración de la vida, en negatividad real» (Hegel $P h d G$ [1966], pp. 124-125). Pero el estoicismo no llega a la certeza absoluta de sí, y permanece como conciencia desgraciada pues es conciencia explícita de su contradicción interna: es lo que Mallarmé conoce muy bien y que comunica a los otros en sus poemas, es lo que funda el carácter crítico de su vida y su poesía.

El vocabulario hegeliano que Sartre utiliza para hablar de Mallarmé no es fortuito, pues no sólo su propia concepción de la negatividad está altamente influenciada por el pensador alemán (Véase Bello 1979, pp. 77 y siguientes) sino que el propio Mallarmé toma de Hegel (a quien conoció gracias a Villiers de L'Isle-Adam) gran parte de su terminología; por ejemplo, en la descripción que hace de los tres momentos de la Belleza en la carta a Lefébure del 27 de mayo de 1867 se puede apreciar el ritmo hegeliano: quietud en lo inmediato (la belleza de la Venus de Milo), paso a lo mediato e inquietud (la belleza de la sonrisa de la Gioconda), reconciliación en sí y para sí del Absoluto-sujeto (la belleza moderna de su Herodías, críticamente consciente de sí misma). 
es un acto, es precisamente porque destruye un ser y provoca que todo el mundo quede obsesionado por una ausencia. De lo que se tratará entonces es de reproducir este movimiento propio del suicidio: «puesto que el hombre no puede crear, pero le queda el recurso de destruir, y puesto que se afirma por el acto mismo que lo anonada, el poema será un trabajo de destrucción». ${ }^{26}$ Citando a Blanchot, Sartre expresa que la poesía será el lenguaje cuya fuerza radica toda en no ser, en evocar la ausencia de todo por su propia ausencia. Mallarmé se arriesga por completo y se descubre en ese arrojo en su esencia de hombre y de poeta: efectiviza la nihilización al abandonar su rebelión adolescente «contra todo», y así puede escribir que «el poema es la única bomba». El pálido y frágil Stéphane se convierte de pronto en terrorista. El poema surgirá del suicidio del poeta, de su «desaparición elocutoria», y se dará la iniciativa a las palabras. Nace de esta manera la poesía crítica, la forma más puramente negativa de la literatura.

\section{LA POESÍA CRÍTICA: NEGACIÓN DEL POEMA, DEL LENGUAJE, DEL MUNDO Y DEL HOMBRE}

Llegamos así al punto central de este trabajo. Si el lenguaje existe cuando se habla, Mallarmé intentará abolirlo mediante un poema en donde nadie habla, donde un silencio ontológico revierte y posibilita una liberación total del sentido. Toda creación, dice Sartre, es un acto que produce un objeto que se vuelve contra ella y cuyo sentido, si lo tiene, emana de él solo. En la literatura clásica la significación es anterior al objeto, quien aparece como un vehículo: pero Mallarmé, que quiere crear un «poema sin los hombres», «rechazará subordinar las palabras a un sentido preconcebido; las dispondrá, al contrario, para que un sentido resulte de su combinación. Sus 'desigualdades' engendrarán tensiones y significaciones parciales que se organizarán en una significación última y total. La unidad de la frase no se deberá a la síntesis de un pensamiento 'trazado' que yuxtapone las palabras una tras otra; será más bien un tornasol, un sentido indefinible que surgirá de la dispersión verbal». ${ }^{27}$ De esta manera la significación explota, pulverizando la estructura total del lenguaje donde lo que quedan son ecos musicales, resabios de luz de las palabras incendiadas. Si la poesía es negación del mundo y del hombre, «el poema es ante todo la negación del poeta»: «el poema, por fin separado de su autor, juego solitario del lenguaje, aparece al lector como un acto inerte, una yuxtaposición azarosa que, justamente, excluye para siempre el

26 Sartre 1986, p. 146. El subrayado es mío.

27 Ibid., p. 147 
azar». ${ }^{28}$ Ésta es precisamente la función del caligrama, no dejar nada librado al azar al mismo tiempo que quita a la palabra todo carácter verbal (léase Un golpe de dados jamás abolirá el azar, poema emblemático). La palabra diluida caligráficamente nos da a ver: en ella el sentido no podrá ser afirmado por el verbo sino descubierto: la significación le vendrá luego como una sobredeterminación. La realidad y el mundo se evaporan en escritura, pues en este caso el sentido es una significación que se vuelve Ser pero que por su pura presencia realiza un vacío, un desfase respecto de la palabra, un «silencio en el seno del silencio», la negación de la palabra-cosa. El poema no debe tanto «darnos» las cosas sino arrebatárnoslas: cada ausencia debe abrirse sobre otra más amplia y universal, para que en el momento en que el lenguaje como poema retome el mundo, éste se ausente enteramente del lenguaje. Se ve así la mecánica de la poética «simbolista» y sugestiva de Mallarmé:

...se debe emplear esta desaparición vibratoria para nombrar otra cosa que no sea el objeto señalado, para que su ausencia sea ante todo realizada como una insuficiencia de los objetos nombrados [...]; no se trata de encontrar las estructuras ideales e inteligibles de lo real, sino de escribir sobre cualquier cosa con cierta técnica que vaciará el objeto elegido de su materia y lo hará funcionar como idea, o sea como unidad sintética y trascendente de la diversidad. ${ }^{29}$

De esta manera, la ausencia total del mundo se realiza en estos poemas alusivos: es el hundimiento de lo real y del lenguaje en el suicidio del poeta. La explosión de colores y formas revela un símbolo sensible que remite a la tragedia humana, disuelta en la nada, pues precisamente «la verdad alcanzada en estos poemas es la Nada: 'NADA / HABRÁ TENIDO LUGAR / SINO EL LUGAR'». ${ }^{30}$

Pero Mallarmé bien sabe que, irónicamente, su tarea es imposible y sus poemas un fracaso. Su intuición crítica le revela a la Poesía su propia imposibilidad, y sin embargo, aquí es donde se encontrará su triunfo. ${ }^{31}$ Una vez que tomó como tema poético la desolación lúcida de un Arte que conoce su imposibilidad, el poema se vuelve objeto para-sí: en él y por él la Poesía se conoce y se destruye, se hace crítica. Todos sus poemas y escritos la reconocen

28 Ibid., p. 148. En efecto, como dirá más adelante: «Desaparición elocutoria del poeta, palabras reducidas a cosas, a fenómenos naturales: el suicidio poético conlleva la destrucción del lenguaje como tal. Así como la abolición de la subjetividad del lector [...]. Sin autor, no hay lector: sólo un testigo azorado de los juegos solitarios del diccionario».

29 Ibid., p. 150

30 Ibid., p. 152

31 «La espiral se tuerce de nuevo sobre ella misma: impotente que canta su impotencia, Mallarmé convirtió su fracaso personal en imposibilidad de la Poesía; y luego, por una nueva inversión, transforma el Fracaso de la Poesía en Poesía del Fracaso» (Ibid., p. 134). 
como tema central, hablan de su imposibilidad (y de lo que es su correlato inmediato, la imposibilidad de ser hombre). En el poema el azar es el que se niega a sí mismo; la poesía, que nace del azar y que lucha contra él, lo abole al abolirse pues su abolición simbólica es la del hombre. No era suficiente que se negara mundo y lenguaje, sino que debía nihilizarse a sí misma gracias al suicidio del poeta. Mallarmé, el «poeta de la Nada», surge como el elegido de su raza, como la encarnación más pura de su época:

Era preciso que la Poesía se alcanzara a sí misma y se negara [...], que se convirtiera en Poesía consciente de sí o Poesía crítica [...]. Proyectado hacia lo Absoluto por su Raza, Mallarmé ha concebido la Poesía bajo su verdadera forma, que es la Negación pura. Pero la noción así formada, o negación de la negación, le ha revelado al Hombre. ${ }^{32}$

La radicalidad del acto de Mallarmé es que se compromete por entero en la destrucción de sí y en la destrucción crítica de la poesía por sí misma para testimoniar y construir una humanidad nueva que críticamente se reconoce como imposible pero como enteramente libre, es decir, que se reconoce como Negatividad absoluta gracias al espejo poético. Abre el campo de juego de toda literatura que se quiere comprometida, instaura el proyecto de una literatura total por la que «no hay escritor, por modesto que sea, que se arriesgue en un libro sin arriesgar la Palabra con él. La Palabra o el Hombre: todo es uno». ${ }^{33}$ Como escribe magistralmente Sartre:

Con Mallarmé nace un hombre nuevo, reflexivo y crítico, trágico, cuya línea de vida es un declinar. Este personaje, del que el ser-para-el-fracaso no difiere esencialmente del ser-para-morir heideggeriano, se proyecta y se junta, se sobrepasa y se totaliza en el drama fulgurante de la encarnación y la caída, se anula y se exalta al mismo tiempo, en fin, hace que exista por la conciencia que toma de su imposibilidad. ${ }^{34}$

\section{CONCLUSIÓN: HACIA UNA POESÍA TOTAL}

De esta manera, con Mallarmé el «Dasein» de la Poesía y del Hombre se equiparan a un punto tal que son un reflejo prácticamente exacto de su mutua imposibilidad: y por ello es que el poema, como objeto-otro-del-para-sí, es quien más y mejor le devuelve al para-sí su imagen negativa, su «cara de sombra», su esencia como negatividad, como ex-sistencia, como pro-yecto arrojado desde la nada hacia la nada en la apertura de un mundo que vive

32 Ibid., p. 132. El subrayado es mío.

33 Ibid., p. 134

34 Ibid., p. 135 
como su situación. Por ello es que el compromiso total de Mallarmé no es solo poético sino, como ya dijimos, humano y social: ${ }^{35}$ pues rechaza y asume su época al mismo tiempo, le devuelve la imagen criticada y negativa de sí, expresa el drama ontológico de todo hombre, el fracaso de toda existencia que pretende sintetizar y resolver definitivamente sus contradicciones. Por eso su literatura lo es todo, y por eso es comprometida. Su poesía crítica nace de los fracasos inherentes al mismo lenguaje, donde los sin-sentidos son utilizados como medios para aproximarse al sentido inarticulable. Aparenta escribir el discurso de la impotencia, que no tiene sentido sino en la medida en que por sus fracasos busca acercarse al objeto que es la «poesía-escapando-a-losazares-del-lenguaje», es decir,

La poesía reflexionando sobre sí afirmándose, más allá de su imposibilidad reconocida, como imaginario puro. Es manifestar la inadecuación del hombre a su proyecto fundamental [...] En el instante en que el poeta declara en su poema: 'he perdido, nada tuvo lugar sino el lugar', él ha ganado [...] puesto que ha dado sin palabras -o mejor dicho haciendo naufragar todas las palabras- una presencia indirecta a lo irrealizable. ${ }^{36}$

Mallarmé, finalmente, aplicó al arte el principio filosófico-político que Sartre luego haría suyo: «hacer, y al hacer hacerse». Fue el primero en plantear la cuestión que décadas después Sartre retomaría y discutiría tan ardientemente: ¿existe algo así como literatura? ¿Cómo puede pensarse un compromiso literario?. Y, lo que es más importante, es quien ha manifestado de una vez y para siempre que la Poesía sí puede comprometerse, de manera complementaria al compromiso de la prosa, en la destrucción y la creación de un mundo nuevo, de un hombre auténtico, de una sociedad nueva, humana, libre. Para Sartre, este poeta nos muestra que la función negativa de la literatura debe abarcarlo todo, hasta el extremo, hasta la muerte: ${ }^{37}$ que sólo mediante el

35 Sartre ampliará esto algunos años después, defendiéndolo contra las acusaciones hechas por su «hermetismo», diciendo que Mallarmé «deseaba que se representara la Tragedia algún día ante lo que él denominaba entonces 'la multitud' -y que concebía como un público de masa (más en una catedral atea que en un teatro) [...]. Mallarmé ligaba sus concepciones órficas y trágicas de la poesía a la comunión de un pueblo más que al hermetismo individual. Éste no era más que un rechazo de la estupidez burguesa. Ciertamente, no pensaba que se debe escribir 'claro' para un público popular. Pero imaginaba que para ese pueblo unido, lo oscuro se tornaría claro» (Sartre 1972 [1973], p. 13).

36 Ibid., pp. 210-211

37 «Si la literatura no es todo, no vale la pena perder en ella ni una hora. Eso es lo que entiendo por 'compromiso'. La literatura se muere si se la reduce a la inocencia, a canciones. Si cada frase escrita no resuena en todos los niveles del hombre y de la sociedad, no significa nada. La literatura de una época, es la época digerida por su literatura» (Sartre 1972, p. 13). 
compromiso radical y existencial en una literatura total, en una poesía crítica, es que se devolverá al mundo, al hombre y al lenguaje su imagen y su sentido verdaderos: la Nada.

\section{REFERENCIAS BIBLIOGRÁFICAS}

BELLO, E. 1979: De Sartre a Merleau-Ponty. Dialéctica de la libertad y el sentido, Murcia, Publicaciones de la Universidad de Murcia.

BLANCHOT, M. 1943 : Faux-Pas, Paris, Gallimard.

CAMPA, L. 1998 : Parnasse, Symbolisme et Esprit nouveau, Paris, Ellipses.

GALLARDO, J.-L. 1998 : Mallarmé et le jeu suprême, Orléans, Paradigme.

HEGEL, G. W. 1807 [1966]: La fenomenología del espíritu, trad. de Roces, W., México D.F., FCE.

LAUPIN, P. 2004 : Stéphane Mallarmé, Paris, Seghers.

LOUETTE, J.-F. 2002: Silences de Sartre, Toulouse, Presses Universitaires du Mirail. MALLARMÉ, S. 1995 : Correspondance. Lettres sur la poésie, Paris, Gallimard.

MALLARMÉ, S. 2013 : Obra poética, trad. de Espejo, M., Buenos Aires, Colihue.

MONDOR, H. 1941 : Vie de Mallarmé, París, Gallimard.

MORTELETTE, Y. 2005 : Histoire du Parnasse, Paris, Fayard.

PAGÈS, C. y SCHUMM, M. (comps.) 2013 : Situations de Sartre, Paris, Hermann Éditeurs.

SARTRE, J.-P. 1972 [1973]: El escritor y su lenguaje y otros textos (Situations IX), trad. de Gudiño Kieffer, Buenos Aires, Losada.

, 1986 [2008]: Mallarmé. La lucidez y su cara de sombra, trad. de Aragüés, Madrid, Arena Libros.

, 1948 [2008]: ¿Qué es la literatura? (Situations II), trad. de Bernárdez A., Buenos Aires, Losada.

, 1952 : Saint Genet: comédien et martyr, Paris, Gallimard.

, 1983: Lettres au Castor, Paris, Gallimard.

Santiago Belloce es profesor de Licenciado en Filosofía (UNSAM), Profesor en Teología (UCA) y docente de Filosofía del Lenguaje (ISPE).

Líneas de Investigación:

Fenomenología hermenéutica, Estética, Filosofía del lenguaje, Heidegger, Sartre, Pensamiento de la Diferencia

Publicaciones recientes:

2019, «La negatividad en la ontología fenomenológica de Jean-Paul Sartre», Factótum 21, pp. 24-35. 
2017, «Langage et existence authentique chez la Lettre sur l'humanisme de Heidegger» Le Médiaphi $\mathrm{n}^{\circ} 14$.

Correo electrónico: santiglm@hotmail.com 
